\title{
PROBABILISTIC SEISMIC FRAGILITY FOR ROCKING MASONRY FAÇADES USING CLOUD ANALYSIS
}

\author{
Armando Benenato $^{1}$, Stefania Imperatore ${ }^{1}$, Gian Piero Lignola ${ }^{2}$, Barbara Ferracuti ${ }^{1}$ \\ ${ }^{1}$ Niccolò Cusano University, Via don Carlo Gnocchi 3, 00166, Rome Italy \\ \{armando.benenato, stefania.imperatore, barbara.ferracuti\}@unicusano.it \\ ${ }^{2}$ Department of Structures for Engineering and Architecture, \\ University of Naples "Federico II", Via Claudio 21, I-80125 Napoli, Italy \\ glignola@unina.it
}

\begin{abstract}
The seismic performance of masonry churches is mainly governed by the out-of-plane mechanisms. Among them, the greater seismic vulnerability can be associated to the out-of-plane mechanism of the façade. If the masonry quality ensures a monolithic out-of-plane behaviour, the dynamic analysis of a rigid rocking block allows a reliable estimation of the seismic capacity of the façade, provided that the element boundary conditions are well assessed. In the present paper, the literature rocking models are adopted for a vulnerability assessment of churches' masonry façades characterized by different geometries. At this aim, fragility curves are defined by means of the Cloud Analysis approach considering earthquakes recorded in the Central Italy area to account for the record-to-record variability.
\end{abstract}

Keywords: Rocking; masonry façades; cloud analysis; fragility curves.

\section{INTRODUCTION}

The seismic performance of historic masonry churches is governed by the local out-of-plane response of the single structural components (i.e., façades, transverse walls, etc.). Among all the macro-elements, the post-earthquake surveys highlight the greatest vulnerability of the façade [1]-[6], which dynamic performance is typically characterized by a rigid-body behaviour.

A common methodology for the dynamic simulation of simple overturning mechanisms is based on rocking motion models where the impacts occurring at the base of the block or against elements preventing inward rotation (i.e. transverse walls or roofings) are accounted for by means of a kinetic energy dampening. The dynamic analysis of the "two-sided rocking" -occurring in the case of isolated elements - was firstly studied by Housner [7]. Subsequently, Yim et al. [8] observed a great sensitivity by the dimensional characteristics of the block or by the 
ground motion shapes, whilst Makris \& Roussos [9] found a dependence of the block overturning on both the earthquake intensity and the pulse length. The first studies on the "one-sided rocking" -developing if the inward rotations are prevented- were performed by Hogan [10], lately the issue was more extensively addressed: the energy dissipation phenomena were experimentally and theoretically investigated by Sorrentino et al. [11]-[12], while a different mechanical model to study the unilateral rocking motion was proposed by Giresini et al. [13]-[14]. All the theoretical models proposed in the scientific literature were applied to investigate the vulnerability of different masonry macro-elements, among which the church façades [15]-[16].

In this paper, the classic rocking models are employed to define fragility curves for five geometries of masonry church façades subjected to unscaled ground motions recorded in the Central Italy area. Aim of the work is the application of a non-linear dynamic procedure, known as Cloud Analysis [17], in which a structural response parameter (i.e. the maximum rotation of the rocking block) and the intensity measures of an as-recorded ground motion are fitted in the logarithmic scale to obtain a linear regression model. The approach was employed for its simplicity and the limited number of required analyses. In the paper, both the two-sided and the one-sided rocking motion are considered. The obtained fragility curves are finally compared to evaluate the influence of the geometrical features of the blocks and of the kinematic mechanism (one-sided or two-sided) on the seismic vulnerability of masonry churches' façades.

\section{MODEL FOR THE ROCKING MOTION OF A MASONRY FAÇADE}

If the masonry can be regarded as a no-tension monolithic material characterized by an infinite compressive strength, a masonry church façade can be studied as a rigid block involved into a rocking motion as a consequence of an earthquake over a certain magnitude.

The analytical model of the rocking mechanism starts from the Lagrange equation and reaches the formulation proposed by Housner in 1963 [7], if the body deformability is neglected and the occurrence of rotations without sliding is assumed:

$$
\ddot{\theta}=-p^{2} \cdot\left[\operatorname{sgn} \theta \cdot \sin (\alpha-|\theta|)+a_{g}(t) \cdot \cos (\alpha-|\theta|)\right]
$$

where $\theta$ is the rotation of the block, $p^{2}=(m \cdot g \cdot R) / I_{0}$ is the dynamic coefficient of the block, $I_{0}=I_{\mathrm{G}}+m \cdot R^{2}$ is the moment of inertia about the two centres of rotation (points $\mathrm{O}$ and $\mathrm{O}$ ' in Fig. $1), I_{\mathrm{G}}$ is the moment of inertia about the centre of gravity, $m$ and $R$ are the mass and the halfdiagonal of the block respectively, $\alpha$ is the inverse of the block slenderness and $a_{g}(\mathrm{t})$ is the ground motion acceleration.

The rocking motion starts if the seismic acceleration exceeds the kinematic acceleration $a_{R M}$ :

$$
a_{R M}=g \tan \alpha
$$

and the overturning condition defines the failure when a rotation of the block under the seismic motion higher than the angle $\alpha$ is attained. This statement may be overcome in the case of forced oscillatory motion: consecutive contrary pulses can in fact bring the system again in an equilibrium condition even if the rotation of the block exceeds the angle $\alpha$.

Eq. (1) can be employed for any simple out-of-plane mechanism, on the condition to properly account for the dissipative phenomena taking place at each impact. Therefore, at the theoretical level, the difference between the one-sided and two-sided rocking behaviour is related only to the kinetic energy damped due to the different boundary conditions. The issue can be assessed considering the velocity reduction experienced by the element after each impact during the two-sided or the one-sided rocking motion. 


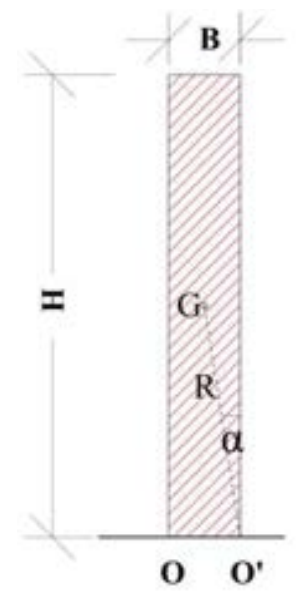

a)

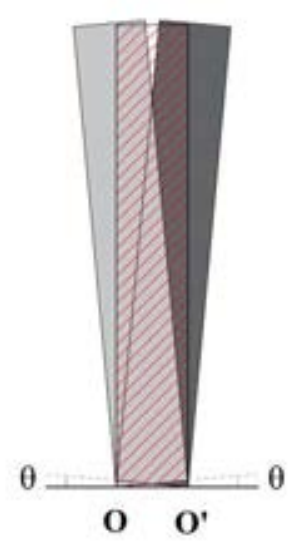

b)

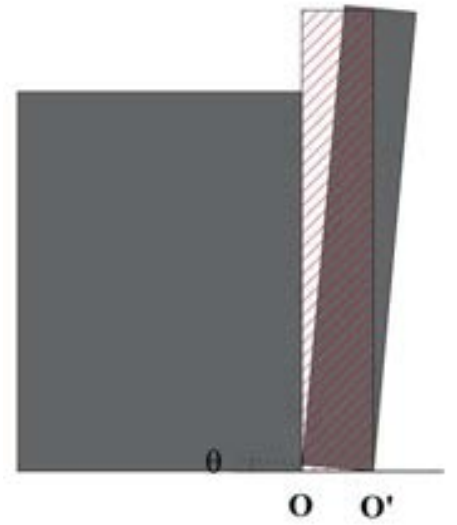

c)

FIGURE 1. Models of the rocking block (the geometrical features are expressed by the base B, the height $H$, the radius vector $\mathrm{R}$, the angle $\alpha$, the center of gravity $\mathrm{G}$ ): a) initial position; b) two sided model; c) one sided model.

In the case of two-sided motion (Fig. 1), the behaviour is governed by the rotation $\theta$ around the two corners $\mathrm{O}$ and $\mathrm{O}^{\prime}$, those alternatively become the centers of block rotation. After each oscillation, the element comes back into the vertical position and an impact on the base occurs. Such rebound effect implies a reduction of the kinetic energy after the impact, with a consequent energy damping. According to the model proposed by Housner in 1963 [7], the reduction in angular velocity due to an impact of infinitesimal duration can be evaluated by means of the

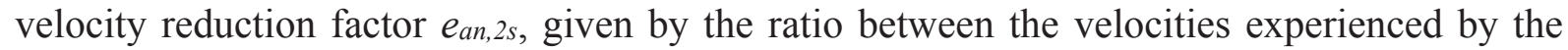
block after and before the impact. By imposing the conservation of the angular moment about the center of rotation before and after the impact, the velocity reduction factor can be evaluated for a rectangular block as:

$$
e_{a n, 2 s}=1-\frac{3}{2} \sin ^{2} \alpha
$$

With Eq. (5) the initial conditions after each impact can be evaluated and the amplitude of the oscillation during the rocking motion can be still estimated by using Eq. (1). The higher the velocity reduction factor, the smaller is the energy loss due to impact and consequently the damping of the rocking motion of the element.

When the rocking motion is admitted only in one direction, as shown in the Figure 1, the block will oscillate around the corner $\mathrm{O}$, and after reaching the maximum rotation it comes back again to its initial position and will impact to the restraint, which prevents the rotation around the opposite corner. In this case the motion is defined one-sided rocking. The influence of the sidewalls on the rocking motion can be studied according to Sorrentino et al. 2011 [12]. In this model the transverse wall is modelled as a fixed restrain. Admitting that there is a little gap between façade and transverse walls, after the first impact against the base, the block experiences an infinitesimal counter-clockwise rotation and a subsequent impact against the upper corner. The latter condition involves an initial change in the rocking hinge and a rotation reversal of the element: the clockwise rotation around $\mathrm{O}$ will cause a third impact, against the base, after which the block has returned to vertical position. According to this approach [12], the analytic transversal velocity reduction factor for the one-sided rocking motion $e_{a n, l s}$, is:

$$
e_{a n, 1 s}=\left(1-\frac{3}{2} \sin ^{2} \alpha\right)^{2}\left(1-\frac{3}{2} \cos ^{2} \alpha\right)
$$


Of course, in the case of one-sided rocking the velocity reduction factor is smaller than the two-sided ones, due to the higher dissipation occurring at each impact.

\section{DYNAMIC ANALYSES}

The seismic performance of typical Italian masonry churches' façades or portion of them have been investigated by means of rocking dynamic analysis. The overturning conditions of masonry churches' façades, involved in earthquake events, is here evaluated with reference to five rigid blocks. In table 1 are reported the principal features of the investigated elements: typology, height $(H)$, base $(B)$, slenderness $\lambda=H / B$, kinematic accelerations $a_{r m}$ (minimum acceleration that causes rocking). With the first set of geometries (1,2 and 3), the incidence of the variation in slenderness is investigated. For the second set (1, 4 and 5), it is analyzed the influence of the base dimension fixed the slenderness. The selected geometries are subjected to the unscaled natural ground motions described in the following.

\begin{tabular}{c|c|c|c|c|c}
\hline Geometry & Typology & Height & Base & $\boldsymbol{\lambda}$ & $\boldsymbol{a}_{\boldsymbol{r m}}$ \\
{$[-]$} & {$[-]$} & {$[\mathrm{m}]$} & {$[\mathrm{m}]$} & {$[-]$} & {$\left[\mathrm{m} / \mathrm{s}^{2}\right]$} \\
\hline F1 & Façade of small church & 6 & 0.6 & 10 & 0.98 \\
\hline F2 & Intermediate façade between 1 and 3 & 4.5 & 0.6 & 7.5 & 1.31 \\
\hline F3 & Façade of uppermost story & 3 & 0.6 & 5 & 1.98 \\
\hline F4 & Façade of big church & 12 & 1.2 & 10 & 0.98 \\
\hline F5 & Plane belfry & 3 & 0.3 & 10 & 0.98 \\
\hline
\end{tabular}

TABLE 1. Principal features of the walls: typology, height, base, slenderness and kinematic acceleration.

With the aim to simulate the performance of the Apennine Churches stricken by the Central Italy seismic sequence, 89 natural accelerograms recorded during the last twenty years in the Central Italy area are considered to account for the record-to-record variability.

89 time-histories characterized by magnitude between 4 and 6.5 has been collected into a database; according to [18], moment magnitude ML lower than 3.5 are excluded. The adopted database covers intervals of peak ground acceleration (PGA) up to $1 \mathrm{~g}$, peak ground velocity (PGV) up to $0.85 \mathrm{~m} / \mathrm{s}$, Housner Intensity (HI) up to $2.8 \mathrm{~cm}$ and Arias Intensity ( $\mathrm{I}_{\mathrm{A}}$ ) up to $7 \mathrm{~m} / \mathrm{s}$.

\begin{tabular}{c|c|c|c|c|c|c|c|c}
\hline ID & Station & Date & Time & $\begin{array}{c}\text { Epicentral Distance } \\
{[\mathrm{km}]}\end{array}$ & $\begin{array}{c}\text { PGA } \\
{[\mathrm{g}]}\end{array}$ & $\begin{array}{c}\text { PGV } \\
{[\mathrm{m} / \mathrm{s}]}\end{array}$ & $\begin{array}{c}\mathrm{I}_{\mathrm{A}} \\
{[\mathrm{m} / \mathrm{s}]}\end{array}$ & $\begin{array}{c}\mathrm{H}_{\mathrm{I}} \\
{[\mathrm{cm}]}\end{array}$ \\
\hline $\mathrm{MZ30}_{2}$ & Amatrice & $30 / 10 / 2016$ & $06: 40: 18$ & 27.2 & 0.48 & 0.48 & 1.54 & 1.22 \\
${\mathrm{~T} 1201_{2}}^{2}$ & Domo & $30 / 10 / 2016$ & $06: 40: 18$ & 22.6 & 0.48 & 0.87 & 2.24 & 2.12 \\
\hline
\end{tabular}

Table 2. Seismic Characteristics of the Selected Natural Ground Motion.

In order to analyze the sensitivity of the selected masonry churches' façades on the shape of the natural ground motion, two records with the same peak ground acceleration were selected. Consequently, the other seismic intensity measures (Peak Ground Velocity, PGV, Arias Intensity, $\mathrm{I}_{\mathrm{A}}$; Housner Intensity, $\mathrm{H}_{\mathrm{I}}$ ) differ as reported in Table 2. In Figure 5 the time-histories of the selected ground-motions are shown. 


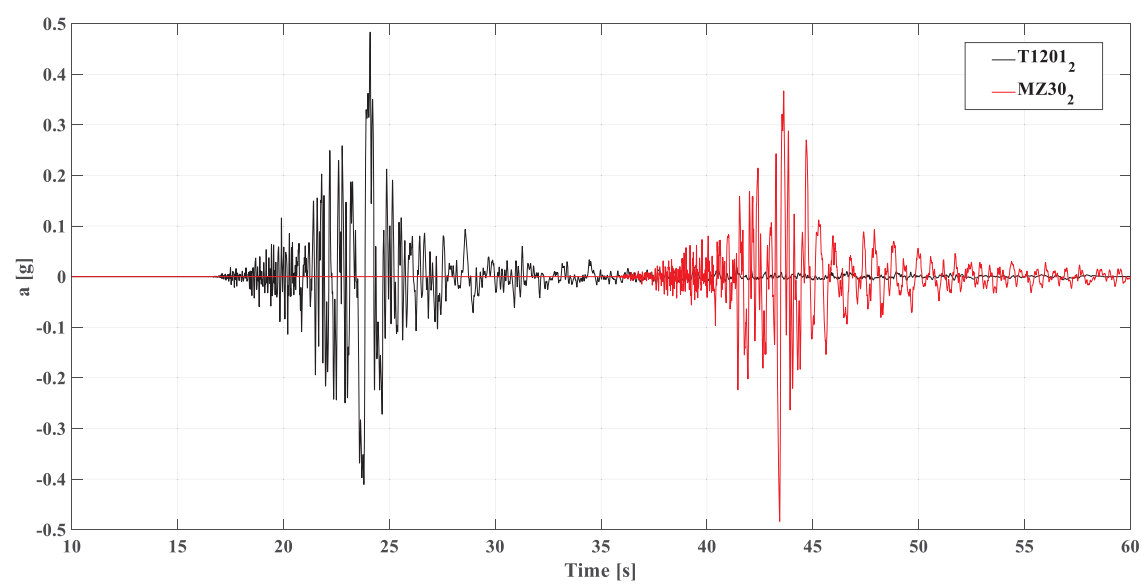

FIGURE 2: Selected ground-motions (the second one is shifted by 35 seconds).

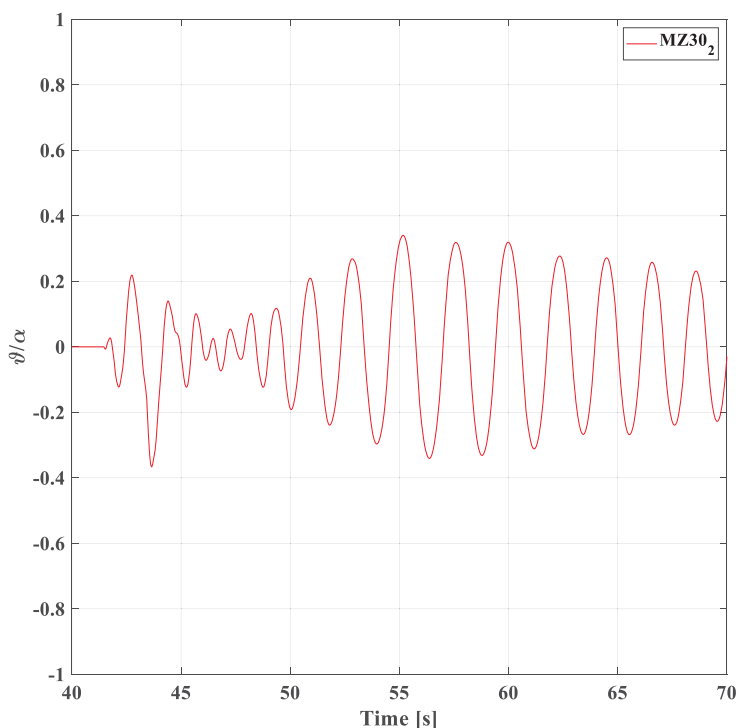

a)

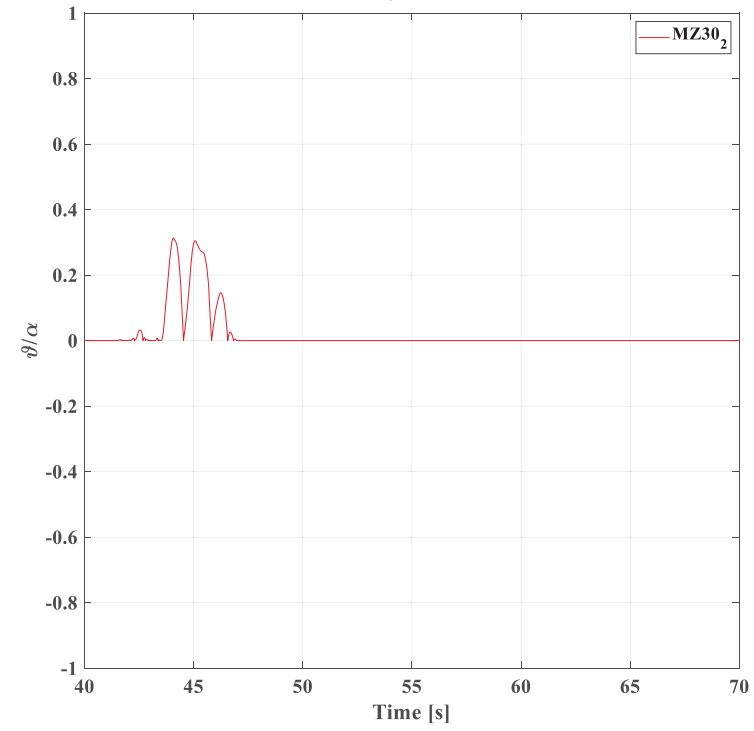

c)

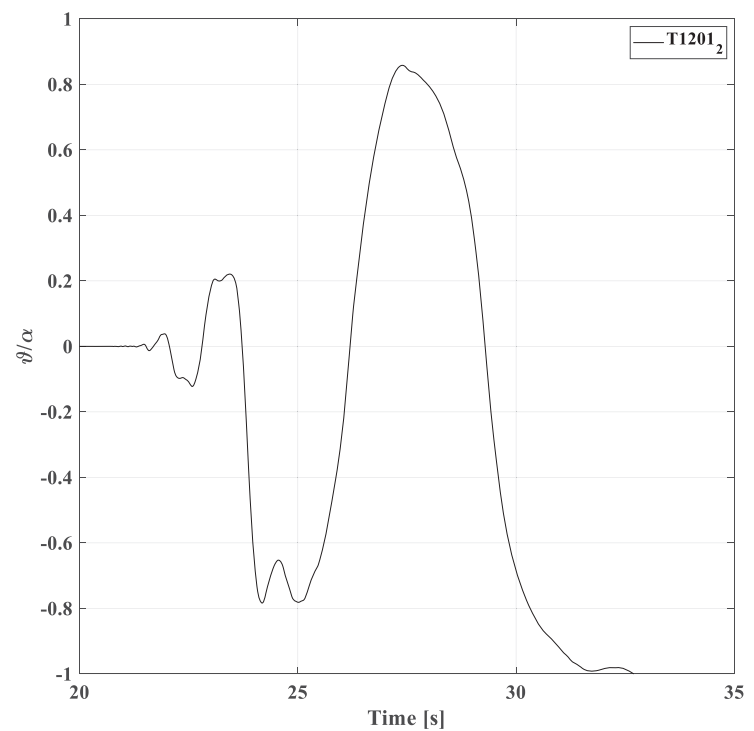

b)

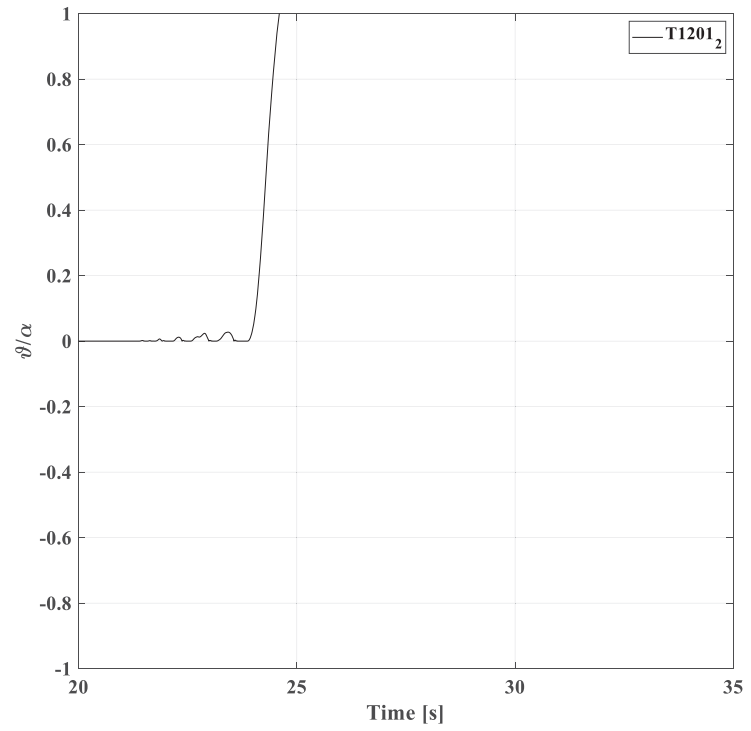

d)

FIGURE 3: Seismic response of façades GEO1 involved in the two-sided rocking motion: a) $\mathrm{MZ}_{3} 0_{2}$ earthquake rocking-inducing; b) T1201 2 earthquake overturning-inducing; c) $\mathrm{MZ30}_{2}$ earthquake rocking-inducing; d) $\mathrm{T} 1201_{2}$ earthquake overturning-inducing. 
The seismic response of the façades in two-sided rocking motion characterized by slenderness $\lambda=10$ (F1) subjected to the MZ302 (Fig.3a) or to the T12012 (Fig.3b) earthquakes is firstly investigated. It is important to observe the different response of the façades to the earthquakes: the $\mathrm{MZ30}_{2}$ time-history induces the rocking motion, while the $\mathrm{T} 1201_{2}$ ground motion -characterized by higher PGV, Arias Intensity and Housner intensity- causes the failure of the element, i.e. the block overturning. Similarly, the one-sided seismic response of the façades with $\lambda=10$ (GEO1) to the $\mathrm{MZ30}_{2}$ (Fig.3c) or to the T12012 (Fig.3d) ground-motions shows the dependence of the façade performance by the earthquake's shape.

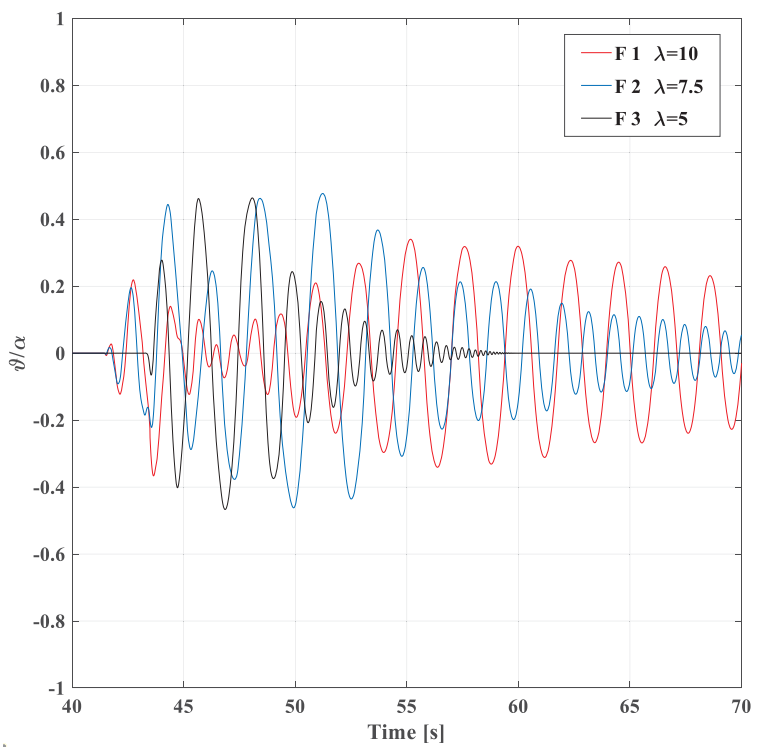

a)

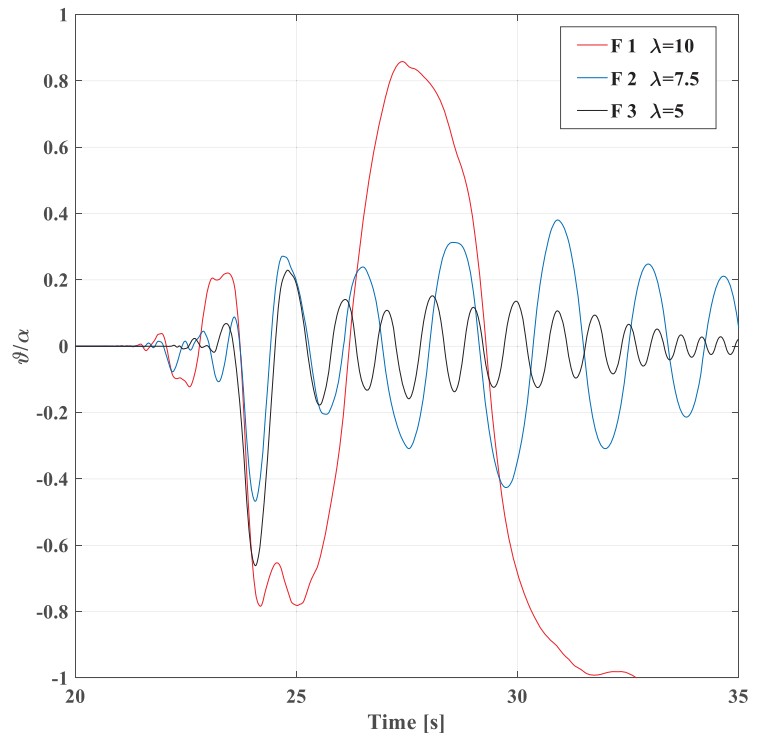

c)

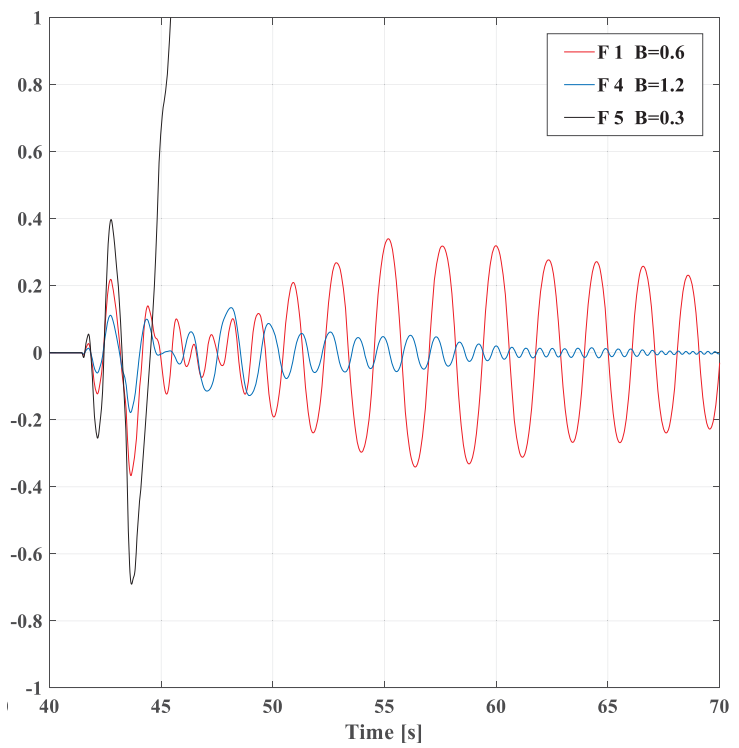

b)

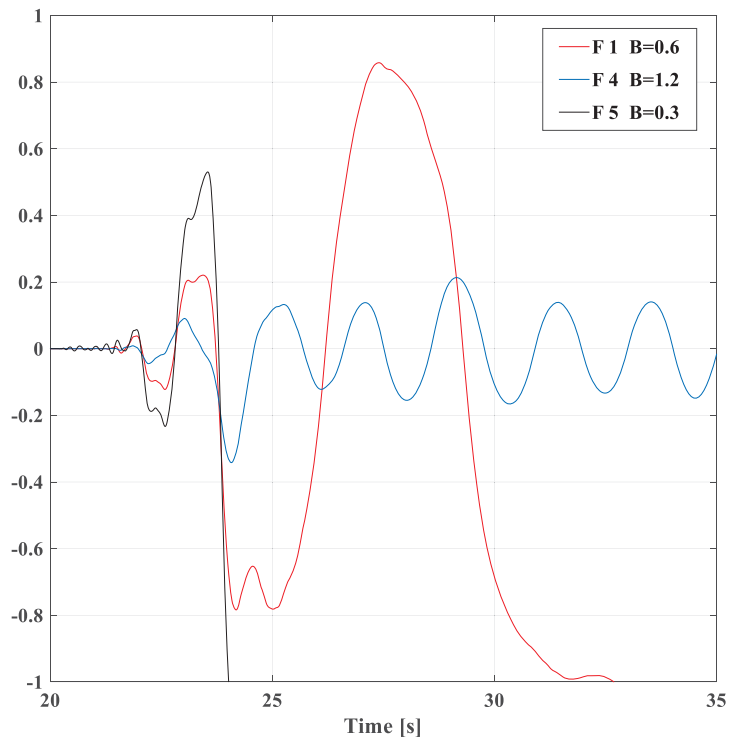

d)

FIGURE 4: Two-sided seismic response of all façades subjected to MZ302: a) influence of the slenderness $\lambda$ for $b=0.6$; b) influence of the base $b$ for $\lambda=10$, and subjected to T12012: c) influence of the slenderness $\lambda$; d) influence of the base $b$.

Finally, the results obtained by the parametric analysis are represented. In Figure 4 the influence of both the façade slenderness and thickness on the dynamic response in two-sided motion is represented. It can be noted that increasing the slenderness (Fig.4a and Fig.4c) the 
rocking motion is delayed, due to the different value of the kinematic acceleration $a_{R M}$. Additionally, once the rocking motion begins, stockier blocks with similar slenderness (F2 and F3) are characterized by similar responses, while the slender block collapses under the heavier earthquake (T12012). With equal slenderness (Fig.4b and Fig.4d) the stabilizing effect due to the base dimension is clear: smaller the base, higher is the block rotations. Therefore, the block with the smaller base (F5) can collapse also under the lighter earthquake ( $\left.\mathrm{MZ30}_{2}\right)$.

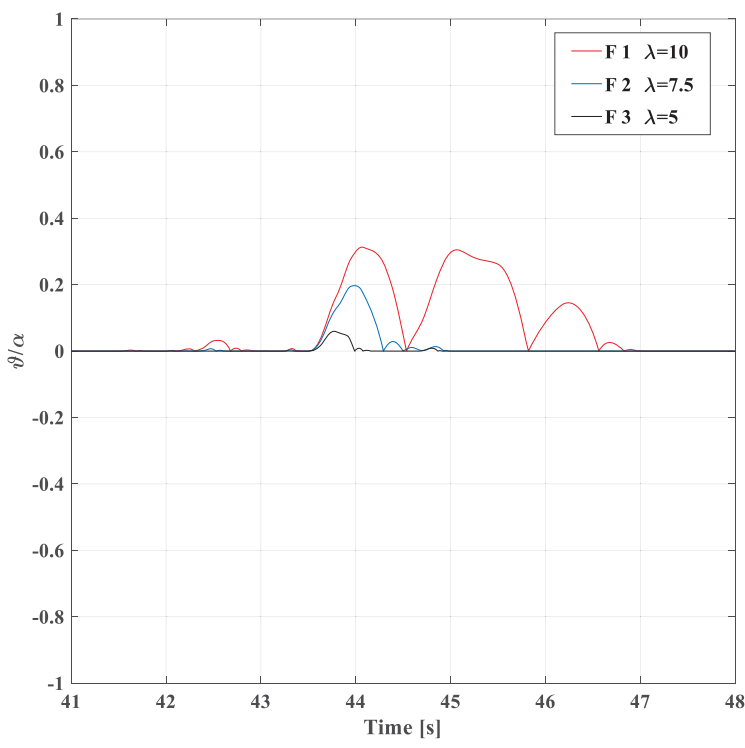

a)

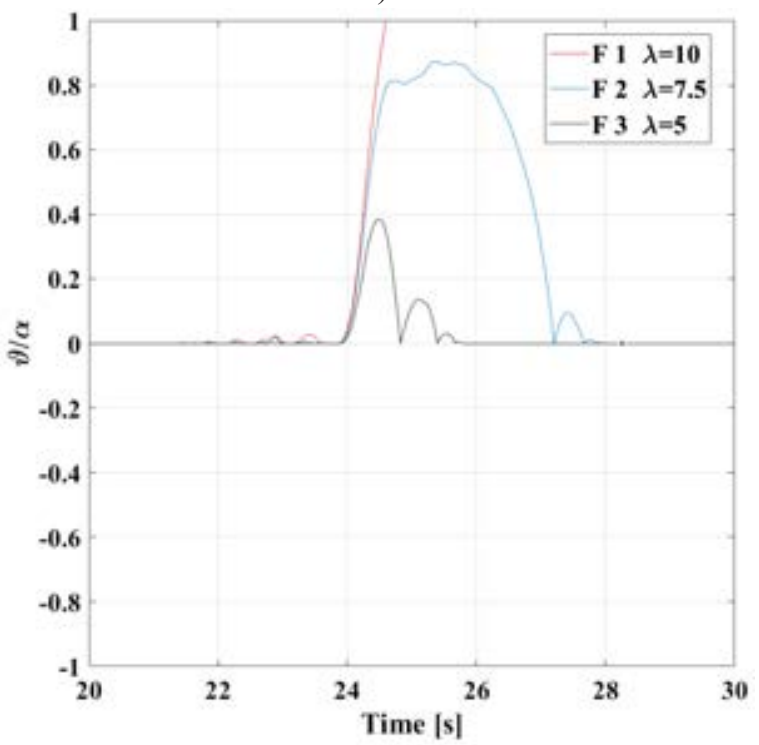

c)

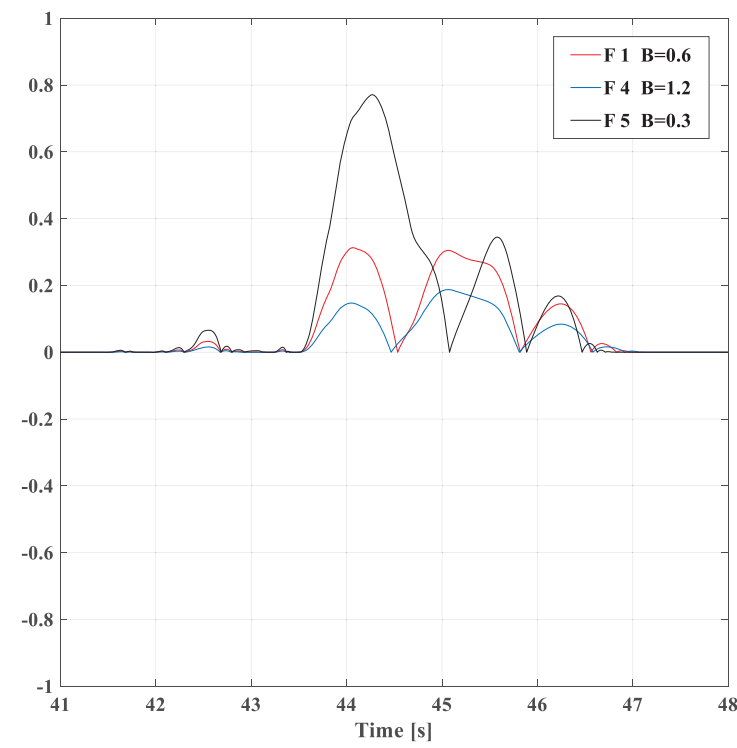

b)

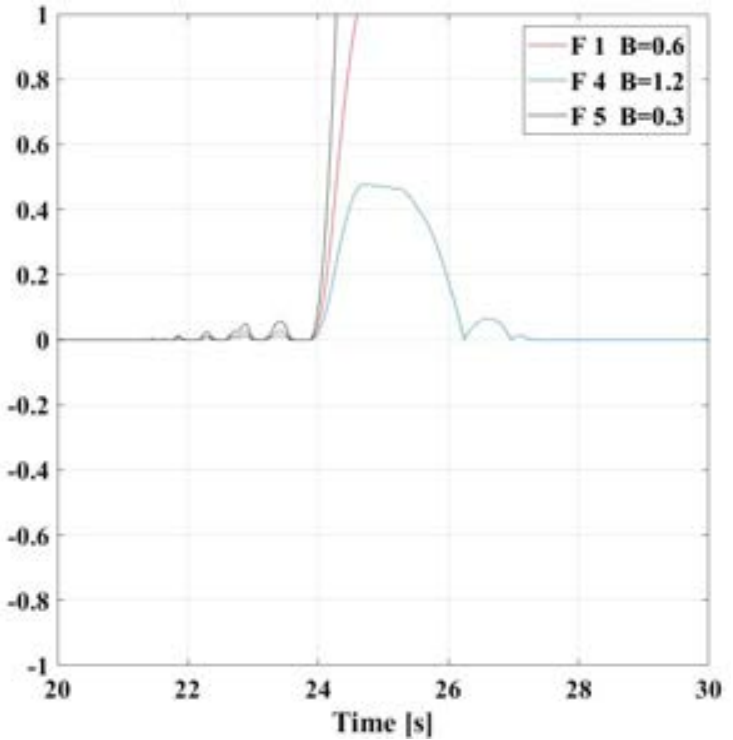

d)

FIGURE 5: One-sided seismic response of all façades subjected to $\mathrm{MZ}_{2} 0_{2}$ : a) influence of the slenderness $\lambda$ for $b=0.6$; b) influence of the base $b$ for $\lambda=10$, and subjected to T12012: c) influence of the slenderness; d) influence of the base.

Concerning the one-sided rocking response, a similar trend can be observed (Fig. 5). Nevertheless, the dynamic response in the one-sided can be more dampened than the two-sided rocking, depending on the ground motion shape as well as for the dissipative effect of the impacts against the sidewalls. In detail, the rocking motion is delayed increasing the slenderness (Fig.5a and Fig.5c), and the slender block collapses under the heavier earthquake (T12012) once the 
rocking motion begins. Moreover, with equal slenderness (Fig.5b and Fig.5d) the dimension of the base has a stabilizing effect on the dynamic response: smaller the base, higher the rotations.

\section{PROBABILISTIC SEISMIC ANALYSIS}

The vulnerability of the selected masonry churches' façades is assessed by estimating the conditional probability $P$ that the seismic demand $D$ (measured with a specific engineering demand parameter, $E D P$ ) is higher than its capacity $C$ for a given value of a seismic intensity (IM). Conventionally, the capacity $C$ is derived by the results of incremental dynamic analysis (IDA) or multi stripe analysis (MSA). In the present work, instead, the Modified Cloud Analysis [17], an innovative and at the same time simple approach, is employed. The effectiveness of the proposed approach has been already established in other structural applications [19].

The structural fragility obtained by a modified cloud analysis in order to include the "collapse cases" [17] can be expressed as the probability that $D$ exceeding the unity for a given $I M$ :

$$
P(E P D>1 \mid I M)=\Phi\left(\frac{\ln \eta_{D \mid I M}}{\beta_{\ln D \mid I M}}\right) \cdot \frac{e^{-\left(\alpha_{0}+\alpha_{1} \ln (I M)\right)}}{1+e^{-\left(\alpha_{0}+\alpha_{1} \ln (I M)\right)}}+\frac{1}{1+e^{-\left(\alpha_{0}+\alpha_{1} \ln (I M)\right)}}
$$

where $\Phi$ is the standardized Gaussian cumulative distribution function (CDF), and $\eta_{D \mid I M}$ and $\beta_{D \mid I M}$ are the conditional median and logarithmic standard deviation (dispersion) of the natural logarithm of $D$ given $I M$ for the No Collapse data. Based on the Cloud Analysis, these two parameters are obtained by performing a logarithmic linear regression on the No-Collapse data.

The parameter $\alpha_{0}$ and $\alpha_{1}$ have been instead evaluated through the logistic regression model applied to all records, distinguishing 1 or 0 depending on the collapse attainment or not [17].

The EPD assumed for the rigid block is the maximum normalized rotation, i.e. the ratio of the maximum rotation $\theta_{\max }$ attained during the dynamic rocking analysis for each ground motion and the overturning limit condition $\alpha=\tan (B / H)$, corresponding to the loss of equilibrium.

Therefore, the EDP can assume the following values: the element is stationary (non-rocking), $\left|\theta_{\max }\right| / \alpha=0$; the rocking motion is enabled, $0<\left|\theta_{\max }\right| / \alpha<1$; the element fails (rocking overturning), $\left|\theta_{\max }\right| / \alpha>1$. A percentage of the rocking blocks overturn, in such a case the EPD attains an arbitrarily large value $\left|\theta_{\max }\right| / \alpha \rightarrow \infty$. The remaining dynamic analyses terminate without overturning, and finite (nonzero) values of $\left|\theta_{\max }\right| / \alpha$ are observed.

In this study, the fragility curves at limit state corresponding to the rocking overturn, is developed. The Figure 6a illustrates the obtained fragility curves at collapse for the façades with different slenderness given $I M=$ PGA. As already observed by the outcomes of dynamic analyses, slender façades are more vulnerable with respect to the squatter one. The Figure $6 \mathrm{~b}$ illustrates the probability of overturning for the façades with different value of $B$. Although the slenderness of the façades is the same, the fragility curve shows an increment in collapse probability decreasing the base dimension. It is worth to note that the fragility curves obtained with the Cloud Analysis for the façades F1, F4 and F5 are comparable to those obtained by Lagomarsino et al. [20] performing the conventional IDA; therefore, the Cloud Fragility approach is reliable for the fragility assessment of elements involved in the two-sided rocking motion.

Concerning the one-sided rocking motion, the fragility curves given $I M=$ PGA are evaluated considering a set of 178 ground motion, 89 in positive direction and 89 in negative direction. In detail, Figure $6 \mathrm{c}$ illustrates the probability of overturning for the façades with different slenderness $\lambda$. It is worth to note that the obtained fragility curve for F1 (slenderness $\lambda=10$ ), is similar to that obtained by Giresini et al. [15] by adopting the conventional IDA approach, therefore the Cloud Fragility is feasible also for the one-sided rocking. 
As already observed for the two-sided case, the façade vulnerability increases with increasing the slenderness. Considering the façades with the same slenderness and different base (Fig. $6 \mathrm{~d})$, the greater vulnerability decreasing the base can be observed, as for the two-sided motion. Comparing the fragility curves for one-sided and two-sided case, in the case of the one-sided rocking motion the fragility curves show higher mean and standard deviation with respect to the two-sided oscillation.

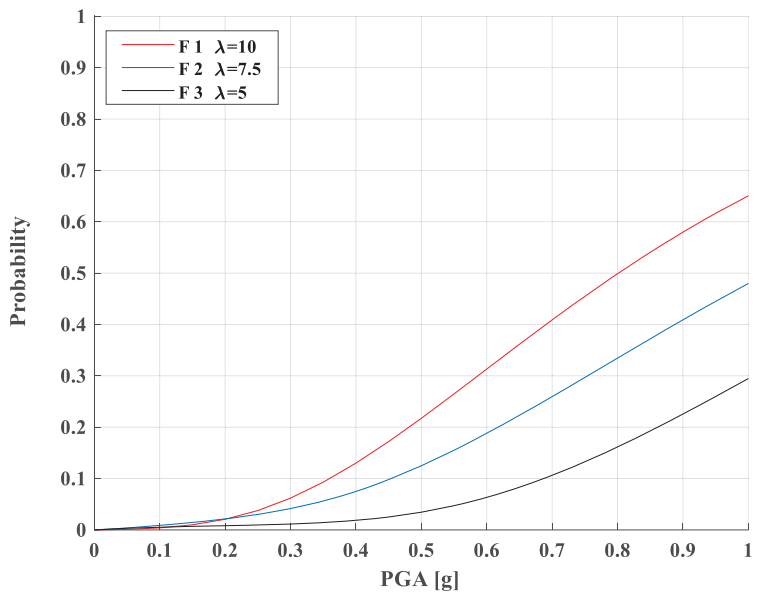

a)

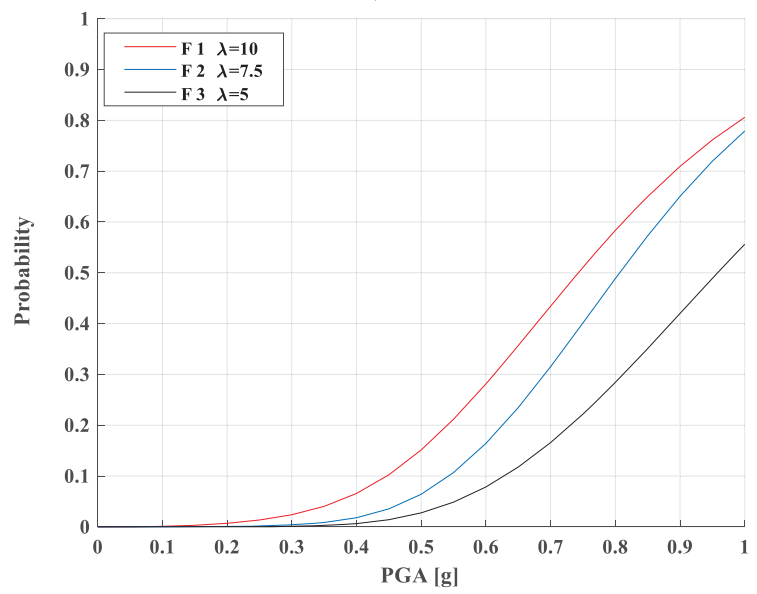

c)

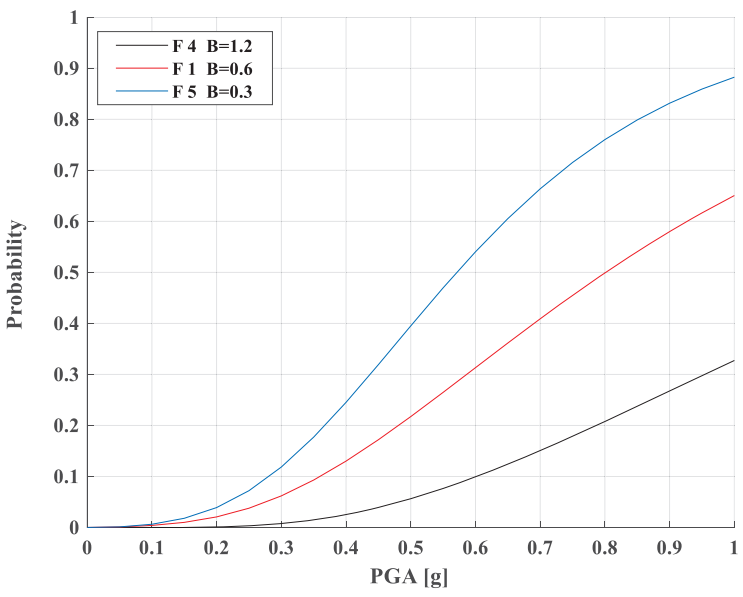

b)

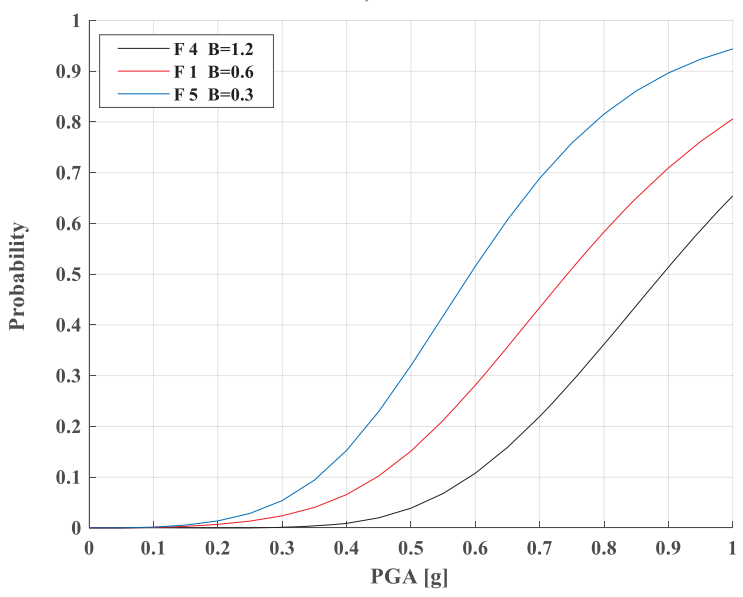

d)

FIGURE 6. Cloud fragility in the two-sided motion: a) influence of the slenderness; b) influence of the base, and Cloud fragility in the one-sided motion: c) influence of the slenderness; d) influence of the base.

The presented fragility curves are developed adopting the PGA as $I M$, because it is in general the most used $I M$ for various structural typologies. Nevertheless, the PGA is not always the most efficient $I M$ for the analyzed structural typologies [14][21][22][23]. In particular, the most efficient $I M$ can be different for the case of two-sided oscillation with respect to the one-side oscillation as already observed in previous studies Further developing will be devoted in evaluating the fragility curves for the most efficient $I M$ for each rocking motion.

\section{CONCLUSIONS}

The goal of this study is the estimation of the fragility curves at collapse for masonry church façades through a Cloud Analysis. At this aim, numerical nonlinear dynamic analyses, performed according to classical literature models, has been performed by applying more than 
89 unscaled records of past earthquakes occurred in the area stricken by the 2016 Central Italy Earthquake. Therefore, the effects of record-to-record variability on the dynamic response was considered. Five different façade geometries were considered, defined observing the masonry churches' façades recurrent in the Central Italy. The obtained fragility curves, that are in line with those derived by other authors adopting different numerical approaches, clearly highlight the influence of the geometry on the seismic vulnerability of façades. Even if it is not meaningful to simply compare the fragility curves for the two-sided and the one-sided rocking motion, since the most efficient seismic intensity measure parameter differ for the two kinematic mechanisms, it should be noted the higher vulnerability for the one-sided compared to the two-sided rocking motion for higher values of PGA. This aspect, already observed by other authors in the past, requires a deeper investigation.

\section{AKNOWLEDGEMENTS}

The authors would like to acknowledge the financial contribution provided by the Italian Network of Seismic Engineering University Laboratories (ReLUIS-DPC 2019-2021 project).

\section{REFERENCES}

[1] F. da Porto, B. Silva, C. Costa, C. Modena "Macro-scale analysis of damage to churches after earthquake in Abruzzo (Italy) on April 6, 2009.” Journal of Earthquake Engineering, 16(6), 739-758 (2012).

[2] Colonna, S., Imperatore, S., Ferracuti, B. 2018. The 2016 central Italy earthquake: Damage and vulnerability assessment of churches. Proceedings of the International Masonry Society Conferences Volume 0, Issue 222279, 2018, Pages 2425-244010th International Masonry Conference, IMC 2018; Milan; Italy; 9 - 11 July 2018.

[3] L. Sorrentino, L. Liberatore, L. D. Decanini, D. Liberatore "The performance of churches in the 2012 Emilia earthquakes.” Bulletin of Earthquake Engineering, 12(5), 2299-2331 (2014).

[4] A. Penna, C. Calderini, L. Sorrentino, C. F. Carocci, E. Cescatti, R. Sisti, A. Borri, C. Modena, A. Prota "Damage to churches in the 2016 central Italy earthquakes." Bulletin of earthquake engineering, 17(10), 5763-5790 (2019).

[5] E. Cescatti, P. Salzano, C. Casapulla, F. Ceroni, F. da Porto, A. Prota "Damages to masonry churches after 2016-2017 Central Italy seismic sequence and definition of fragility curves.” Bulletin of Earthquake Engineering, 1-33 (2019).

[6] P. Salzano, C. Casapulla, F. Ceroni, A. Prota "Seismic vulnerability and simplified safety assessments of masonry churches in the Ischia Island (Italy) after the 2017 earthquake. "International Journal of Architectural Heritage, 1-27 (2020).

[7] G.W. Housner "The Behaviour of Inverted Pendulum Structures during Earthquakes." Bull Seism Soc Am, 53 (2), 403-17 (1963).

[8] C.S. Yim, A.K. Chopra, J. Penzien "Rocking response of rigid blocks to earthquakes." Earthquake Engineering \& Structural Dynamics, 8(6), 565-587 (1980). 
[9] N. Makris, Y. S Roussos "Rocking response of rigid blocks under near-source ground motions". Geotechnique, 50(3), 243-262 (2000).

[10] S.J. Hogan "On the motion of a rigid block, tethered at one corner, under harmonic forcing." Proceedings of the Royal Society, Mathematical and Physical Sciences, 439(1905), 35-45 (1992).

[11] L. Sorrentino, S. Kunnath, G. Monti and G. Scalora, "Seismically induced one-sided rocking response of unreinforced masonry façades". Eng Struct, 30(8), 2140-2153 (2008).

[12] L. Sorrentino, O. AlShawa and L.D. Decanini "The Relevance of Energy Damping in Unreinforced Masonry Rocking Mechanisms. Experimental and Analytic Investigations." Bull Earth Eng, 9 (5), 1617-42 (2011).

[13] L. Giresini, M. Fragiacomo and M. Sassu "Rocking analysis of masonry walls interacting with roofs.” Eng Struct, 116, 107-120 (2016).

[14] L. Giresini and M. Sassu "Horizontally restrained rocking blocks: evaluation of the role of boundary conditions with static and dynamic approaches". Bull Earth Eng, 15(1), 385410 (2017).

[15] L. Giresini, C. Casapulla, R. Denysiuk, J. Matos and M. Sassu "Fragility Curves for Free and Restrained Rocking Masonry Façades in One-Sided Motion." Eng Struct, 164, 195213 (2018).

[16] S. Colonna, S. Imperatore and B. Ferracuti "Fragility curves of masonry churches façades". COMPDYN 2019-7th ECCOMAS Thematic Conference on Computational Methods in Structural Dynamics and Earthquake Engineering, M. Papadrakakis, M. Fragiadakis (eds.) Crete, Greece, 24-26 June (2019).

[17] Jalayer, F., Ebrahimian, H., Miano, A., Manfredi, G., \& Sezen, H. (2017). Analytical fragility assessment using unscaled ground motion records. Earthquake Engineering \& Structural Dynamics, 46(15), 2639-2663.

[18] Cornell C. A., Jalayer F., Hamburger R. O and Foutch D. A. "Probabilistic basis for 2000 SAC federal emergency management agency steel moment frame guidelines". J Struct Eng, 128(4), 526-533 (2002).

[19] Miano, A., Sezen, H., Jalayer, F., \& Prota, A. (2019). Performance-based assessment methodology for retrofit of buildings. Journal of Structural Engineering, 145(12), 04019144.

[20] Lagomarsino, S. (2015). Seismic assessment of rocking masonry structures. Bulletin of earthquake engineering, 13(1), 97-128.

[21] S. Belliazzi, G.P. Lignola and E. Cosenza (2021). Dynamic response of asymmetric bodies assuming a rocking behavior". Proceedings of the Institution of Civil Engineers Structures and Buildings. DOI: 10.1680/jstbu.20.00151

[22] L. Sorrentino, R. Masiani and L.D. Decanini "Overturning of rocking rigid bodies under transient ground motions”. Struct Eng Mech, 22(3), 293-310 (2006).

[23] Benenato A., Imperatore S., Ferracuti B. and Lignola G. P. "Evaluation of the most efficient IM for the vulnerability assessment of masonry façades". In AIP Conference Proceedings (Vol. 2293, No. 1, p. 240007). AIP Publishing LLC. (2020, November). 